\title{
Developmental stages of red the spider mite, Oligonychus coffeae Neitner (Acari: Tetranychidae) infesting rose
}

\author{
M.Haque, A. Wahab, N. Naher and Afroza Begum \\ Department of Zoology, Rajshahi University, Rajshahi-6205 Bangladesh
}

\begin{abstract}
The experiment was conducted to study the duration of different developmental stages of Oligonychus coffeae Nietner in six generations in different seasons of the year. The eggs of $\mathrm{O}$. coffeae developed to adult within the shortest duration of $5.30 \pm 0.16$ days at $30.28^{\circ} \mathrm{C}$ and $76.00 \%$ $\mathrm{RH}$ in June, but it took $12.91 \pm 0.21$ days at $19.80^{\circ} \mathrm{C}$ and $75.41 \% \mathrm{RH}$ in January. The highest temperature accelerated the developmental rate and reduced the duration of developmental stages. Temperature exerted significant effect on all the developmental stages of O. coffeae except deutonymph. But the relative humidity had no significant effect except deutonymph.
\end{abstract}

Key words: Developmental stages, red spider mite, Oligonychus coffeae rose

\section{Introduction}

The red spider mite (RSM), Oligonychus coffeae Neitner belongs to the group of acarines known as Acariformes, in the suborder Prostigmata, and the family Tetranychidae. The RSM is a pest of broad-leaved evergreens, reported from 14 countries in four continents and feeding on 34 different plant species of 15 families (Borrer, et al. 1989). A cool weather pest, RSM develop into damaging populations in early spring and late fall. These mites thought to aestivate in the egg stage during summer, with small populations becoming active during cool periods (Borrer, et al. 1989).

Common host of RSM are rose (Rosa damascena) Azalea (Rhododendron spp.), coffee (Coffea arabica) and camellias (Camellia japonica). In Bangladesh it is reported from the northern part infesting rose with the high population in cooler months (Biswas 2005). Oligonychus coffeae is an important pest of rose, where its high population damage the leaf and resist the development of the plant. The leaves sometimes are deformed and fall off. Its control is essential to get quality plants. But before taking any control measure to be effective the knowledge of its biology or development is essential. The present work was designed to study its biology in different seasons of the year.

\section{Materials and Methods}

The duration of different developmental stages of $O$. coffeae was studied on excised leaf disc of rose in the laboratory. Leaf disc were made with fresh rose leaf without mite infestation. Each disc was circular in appearance with $2 \mathrm{~cm}$ diameter. The leaf discs were placed on cotton bed in petridish facing the surface upward. The cotton bed was kept wet by soaking with water twice daily so that the discs remained fresh.

The adult female mites, reared for laying eggs, were collected from laboratory culture. They were collected from the interior garden of 3rd Science Building of Rajshahi University where they appeared naturally. One adult female was transferred to each disc for laying eggs. The discs containing adult females were checked after 6 hours of mite transfer. The mites were removed if at least one egg was found. Keeping only one egg on each disc the others were destroyed by needle. The petridishes were covered by lid leaving a small gap to avoid excessive moisture inside the petridish. The discs were checked after every 24 hours and the stages of development were noted till the appearance of adulthood. The leaf disc were changed after 3 to 4 days. Thirty discs were prepared for each generation where they were maintained till the adulthood to record the duration of different developmental stages. The immatures were transferred to new disc carefully with the help of hair brush.

The experiment was conducted from $1^{\text {st }}$ January to $30^{\text {th }}$ June 2007. The duration of different developmental stages were recorded for six generations. Temperature and relative humidity were recorded during the entire period of the study

\section{Result and Discussion}

The mean duration of different developmental stages of $O$. coffeae along with average temperature and relative humidity are presented in the Table 1 . The duration of all the developmental stages were longer in cooler months. The life cycle was completed within shortest duration in the sixth generation in the month of June. But it took the longest time in the month of February.

Temperature affected all the developmental stages of O. coffeae. Due to higher temperature the development occurred rapidly and the duration of different developmental stages were shortened except the deutonymphal period. Temperature exerted the significant effect on all the developmental stages except deutonymph. The relative humidity on the other hand exerted no effect except the deutonymphal period where the higher relative humidity significantly shortened the duration of deutonymphal duration. 
Extensive research had been done on the biology of different species of spider mites. Most of the works are related to the effect of temperature. Among them the important are of Sabelis (1981), Northcraft and Watson (1987), Deciyanto et al. (1989), Tsai et al. (1989), Al-Mallak and Abdalla (1990) and Shih (1999). The result of present investigation agreed with the findings of them. Their results show the great effect of temperature on the development of different species of Tetranychus. This experiment also found the significant effect of temperature on the developmental stages of $\mathrm{O}$. coffeae. The higher temperature accelerated the developmental rate and reduced the duration of developmental stages. The life cycle of $O$. coffeae completed within 5.30 days at $30.28^{\circ} \mathrm{C}$ and 12.97 days at $18.80^{\circ} \mathrm{C}$.

Table 1. The mean duration (in days) of different developmental stages of $O$. coffeae infesting rose.

\begin{tabular}{|cccccccc|}
\hline \multirow{2}{*}{ Gener-ation } & \multicolumn{3}{c}{ Different developmental stages (Mean \pm SE) } & \multicolumn{3}{c|}{ Average temp. } & Average RH \\
\cline { 2 - 7 } & Htching period & Larval period & Protonymp-hal period & Deutonym-phal period & Total & \\
\hline 1 & $5.90 \pm 0.24$ & $2.70 \pm 0.18$ & $2.70 \pm 0.10$ & $1.80 \pm 0.11$ & $12.11 \pm 0.20$ & 17.46 & 75.41 \\
2 & $7.03 \pm 0.20$ & $2.13 \pm 0.06$ & $1.83 \pm 0.06$ & $2.00 \pm .09$ & $12.97 \pm 0.21$ & 19.80 & 65.50 \\
3 & $4.23 \pm 0.16$ & $2.13 \pm 0.11$ & $1.36 \pm 0.08$ & $2.16 \pm 0.08$ & $9.90 \pm 0.20$ & 26.06 & 50.03 \\
4 & $2.17 \pm 0.12$ & $1.83 \pm 0.11$ & $1.30 \pm 0.08$ & $1.83 \pm 0.11$ & $7.50 \pm 0.22$ & 31.76 & 60.96 \\
5 & $1.60 \pm 0.09$ & $1.33 \pm 0.08$ & $1.10 \pm 0.05$ & $1.47 \pm .10$ & $5.50 \pm 0.16$ & 29.43 & 72.32 \\
6 & $1.47 \pm 0.09$ & $1.30 \pm 0.08$ & $1.13 \pm 0.06$ & $143 . \pm 0.09$ & $5.30 \pm 0.16$ & 30.28 & 76.00 \\
\hline F & 211.86 & 21.90 & 13.94 & 8.11 & 283.68 & & \\
LSD & 0.378 & 0.089 & 0.181 & 0.239 & 0.456 & \\
r (temp) & $-0.930^{* *}$ & $-0.832^{*}$ & $-0.902^{* *}$ & -0.445 & $-0.900^{* *}$ & \\
r (RH) & -0.147 & -0.205 & 0.255 & $-0.809 *$ & -0.231 & \\
\hline
\end{tabular}

\section{References}

Al-Mallak, N. N. \& Abdalla S. A. 1990. On the biology of strawberry mite, Tetranychus turkestani Ugarov and Nikoloski (Tetranychidae: Acariformes) and the susceptibility of three gladiolus cultivars to infestation under greenhouse condition. Arab J. Plant Prot. 8(1): 21-24.

Borror, D, J, Triplehorn, C, A, \& Johnson, N, F, 1989. An Introduction to the Study of Insects. Saunders College Publishing, 875pp.

Deciyanto, S., Amir, M., Trisawa, I. \& Harijanto, M. 1989. Study on biology and population development of Tetranychus sp. (Tetranychidae: Acarina) on Mentha spp. Pembaritaan Penilitian Taneman Industri (Indonesia). 15(10): 9-14.
Northcraft, P. D. \& Watson, T. E. 1987. Developmental biology of Tetranychus cinnabarinus (Boisduval) under three temperature regimes. Southwestern Entomologist 12(1): 45-50.

Sabelis, M. W. 1981. Biological control of two-spotted spider mites using phytoseiid predators. Part 1. Modeling the predator-prey interaction at the individual level. Agricultural Research Reports No. 910. Wageningen, Netherlands.

Shih, C. I. T. 1999. Population ecology and its application on tetranychid and phytoseiid mite. Chinese J. Entomol. 126: 25-48.

Tsai, S. M., Kung, K. S. \& Shih, C. I. 1989. The effect of temperature on life history and population parameters of kanzawa spider mite Tetranychus kanzawai Kishida (Acari: Tetranychidae) on tea. Plant Prot. Bull. Taiwan 31(2): 119-130.

Manuscript received on 15.11.07, accepted on 08.01 .08 